\section{XAFS XI and new sources in Europe - SLS, SOLEIL and DIAMOND}

\author{
S. Samar Hasnain, ${ }^{a}$ Hiromichi Kamitsubo ${ }^{b}$ and \\ Dennis M. Mills ${ }^{c}$
}

asynchrotron Radiation Department, CLRC Daresbury Laboratory, Warrington WA4 4AD, Cheshire, UK, ${ }^{b}$ SPring-8, JASRI, Sayo-gun, Hyogo-ken 678-5198, Japan, and ${ }^{c}$ Advanced Photon Source, Argonne National Laboratory, 9700 South Cass Avenue, Argonne, IL 60439, USA

This issue brings together papers from the 11th International conference on X-ray Absorption Fine Structure (XAFS XI) held in Ako, near SPring-8, in July 2000. This is one of the major synchrotron radiation conferences, held every two years since 1981 when the first international meeting of XAFS experts was held in Daresbury, coincident with the operation of the first of the second-generation dedicated synchrotron radiation sources. The XAFS conferences have evolved over the years and the size of the XAFS community has increased beyond the expectations of any of the pioneers of XAFS, several of whom were present at the conference and whose contributions form part of this issue. We are particularly pleased to see the article from Ed Stern, where we are privileged to witness his personal recollection of the development of XAFS into a structure-determination technique. This, together with the historical account from Farrel Lytle published earlier [J. Synchrotron Rad. (1999), 6, 123134], is likely to prove of immense interest to the current and future generations of synchrotron radiation scientists.

Like XAFS X, the papers for this Proceedings issue were refereed to the usual standards of the Journal of Synchrotron Radiation, even though the contributed papers are produced from camera-ready manuscripts. The camera-ready manuscripts were prepared only after the completion of the review process. The papers for this conference were handled by Journal of Synchrotron Radiation Co-editors and Guest Editors (Arvanitis, Asakura, Goulon, Gurman, Heald, Kemner, Kosugi, Lee, Michalowicz, Murata, Nomura, Ohta, Oyanagi, Rehr, Tröger) who selected the referees and followed the normal reviewing procedure where referees were given up to six weeks to carry out rigorous refereeing. As a result, in a large number of cases substantial revision to the original manuscript took place. Despite much effort from the Co-editors and Guest Editors, a significant number of papers were not acceptable. We believe that this effort is reflected in the improved quality of the Proceedings and are grateful to the Co-editors, Guest Editors and large number of referees for their effort. The Proceedings of this conference has steadily grown in size and no doubt will continue to do so in the future, especially considering that several new sources are on the horizon in Europe.

SLS, the Swiss Light Source, became the latest third-generation synchrotron radiation source to come on-line. SLS, at the Paul Scherrer Institute located close to Zurich, had its first stored beam on 15 December 2000, four years after the Swiss Government declared its support for the project (20 November 1996). On 19 December, $1.6 \mathrm{~mA}$ was stored with a lifetime of $8 \mathrm{~h}$. This is tremendous progress since the commissioning of the booster in August-September 2000. All those who have been involved with the project should be congratulated. The SLS storage ring is a 12 -cell TBA $\left(8^{\circ}-14^{\circ}-8^{\circ}\right)$ lattice of circumference $288 \mathrm{~m}$ with six straight sections of length $4 \mathrm{~m}$, three of length $7 \mathrm{~m}$ and three of length $11 \mathrm{~m}$. The lattice is designed to provide an emittance of $4-5 \mathrm{~nm}$ rad at $2.4 \mathrm{GeV}$ and $400 \mathrm{~mA}$ and
Touschek limited beam lifetime of $3.5 \mathrm{~h}$ in the presence of undulators with $4 \mathrm{~mm}$ gap. User operation of SLS is scheduled to start in August 2001 with the installation of four beamlines. Two of the beamlines will cover the lower photon energy range (for surface and interface microscopy and surface and interface spectroscopy - both equipped with undulators generating left- and right-circular polarized light), and two will cover the higher energy range (for protein crystallography with an in-vacuum mini-undulator and for materials science with a mini-gap wiggler). Fig. 1 shows Albin Wrulich and colleagues celebrating the first SLS beam.

We reported in May 2000 the debate on the French and UK's new sources, SOLEIL and DIAMOND. On 13 March 2000, the UK's science minister announced the location of the joint UK-French project DIAMOND to be at the Rutherford Appleton Laboratory near Didcot in Oxfordshire. On 21 March, the French Parliament reported, 'Because of the extra cost associated with the access for users to machines abroad, a share in Anglo-French, German or Swiss machines can only be a supplementary investment in certain fields, such as biology, but certainly not a solution replacing a national synchrotron source'. This strong advice was heard by the new French Minister Roger-Gerard Schwartzenberg who announced the resurrection of the SOLEIL project on 11 September 2000 and also announced that it will be built in Saclay, close to the LURE site, to benefit from the available expertise and the local scientific and technical strength. This decision has brought the much needed good news to the LURE staff and the French synchrotron radiation community, as well as a relief to the international community that synchrotron radiation science will continue to thrive rigorously in France. The Ministerial announcement went into some detail about the SOLEIL project and confirmed the main characteristics of the foundation phase report for the SOLEIL project (the so-called APD document). Dr Denis Raoux, former Director of the Crystallography Laboratory in Grenoble and a well known synchrotron radiation specialist from his pioneering days of LURE, has been appointed as the first SOLEIL Director. Dr Michèle Sauvage-Simkin, expert in surface science and X-ray imaging, has been appointed Scientific Director. Dr J. M. Filhol, former Machine Director at ESRF, is

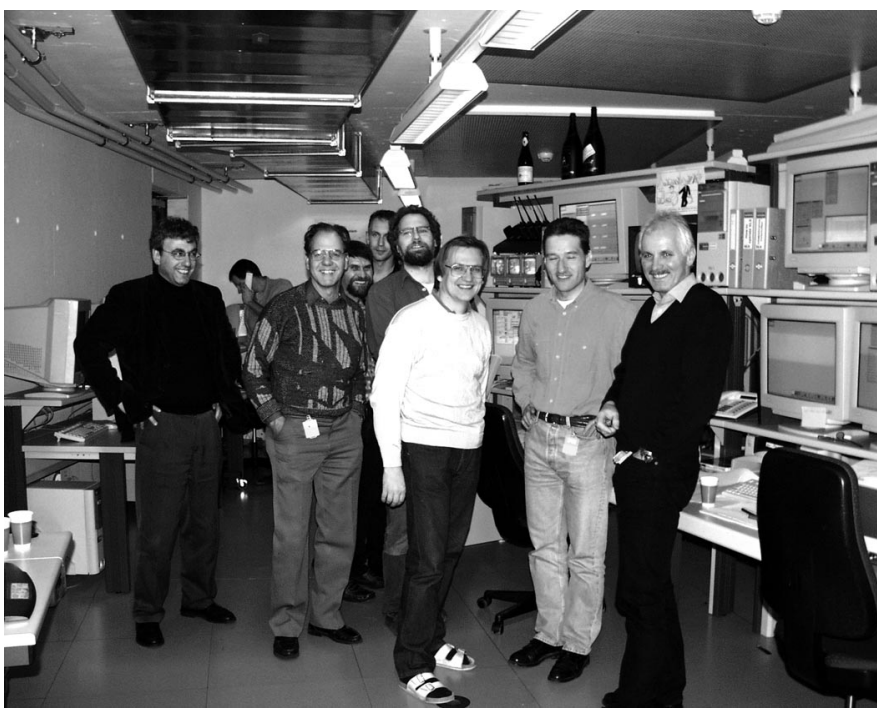

Figure 1

Albin Wrulich (front row far right) celebrates the first SLS beam with his colleagues Timo Korhonen, Thomas Schilcher, Lenny Rivkin, Werner Joho and Andreas Streun. 
appointed as the Machine Director for SOLEIL. The machine energy will be $2.5-2.75 \mathrm{GeV}$ with $3 \mathrm{~nm}$ rad emmittance. Fourteen straight sections will be available for insertion devices. The construction phase is expected to start early in 2002 for the source and initial ten beamlines. The first operation is planned to take place in 2005 with the further build-up of beamlines to a total of 24 over the next three years. It is expected that the beamlines will be divided equally between hard X-rays and soft X-rays/UV and that there will be four beamlines devoted to biology.

The progress on DIAMOND has been somewhat slow. A project Director is yet to be appointed and the nature of organization is yet to be settled. DIAMOND is currently in the early stages of the design phase; hence, the final parameters have not been established but it is agreed that it will be a 24-cell $3.0 \mathrm{GeV}$ storage ring with sixfold symmetry where seven beamlines are expected to be operational from day one. At least three of these are expected to be for protein crystallography/structure genomics. The target emittance of 2$2.5 \mathrm{~nm}$ rad is being set and the lengths of straights are anticipated to be $18 \times(4.5-5 \mathrm{~m})$ and $6 \times(8-9 \mathrm{~m})$. Its circumference is $\sim 530 \mathrm{~m}$. It is likely that a superconducting RF system will be used as it offers greater flexibility, stability and upgrade potential in both current and energy. Top-up injection is being considered to improve the beam lifetime, especially if small-gap insertion devices are used. The current minimum lifetime target is $10 \mathrm{~h}$. The target date for first operation is mid-2006; the 'official' date is expected to be determined following further detailed design work.

In November 1997, the three European synchrotron radiation projects DIAMOND, SLS and SOLEIL signed an agreement to establish a general framework of cooperation. At the time it appeared that the three projects would progress on a similar time scale. Who would have guessed at the time that the three projects would be so different in their realization? There are important lessons to be learnt about the decision-making process and the way funding is made available for these major projects. Even though the three projects have progressed differently, exchange of information and know-how between the three countries has been excellent and one hopes that these will strengthen now that the three projects are 'on-track'. 